2018-09

Degrees of freedom: college-based higher education students' choices and views on the top-up mode of higher education

\title{
McKenzie, L
}

http://hdl.handle.net/10026.1/12971

10.1080/13596748.2018.1490086

Research in Post-Compulsory Education

Taylor \& Francis (Routledge)

All content in PEARL is protected by copyright law. Author manuscripts are made available in accordance with publisher policies. Please cite only the published version using the details provided on the item record or document. In the absence of an open licence (e.g. Creative Commons), permissions for further reuse of content should be sought from the publisher or author. 


\section{Degrees of Freedom: College Based Higher Education Students' Choices and Views on the Top-up Mode of Higher Education}

Liz McKenzie $^{1}$ and Cathy Schofield ${ }^{2 *}$

${ }^{1}$ Institute of Education, Plymouth University, Devon, UK; ${ }^{2}$ Social Science Department, Truro College, Cornwall, UK.

*corresponding author

Cathy Schofield

Social Science Department

Truro College

Truro

Cornwall

UK

TR1 3XX

01872267517

CathyS@Truro-Penwith.ac.uk

Liz McKenzie has 10 years' experience teaching on Higher education programmes within in further education. She currently teaches on postgraduate programmes, within the Plymouth University Institute of Education. Her research interests include the long term impact of HE study on mature learners; staff and student perspectives of college based higher education; the use and experience of reflection among teacher educators and trainee teachers; and the role of writing for professional development.

Cathy Schofield has been lecturing sport and exercise psychology on higher education courses in college settings for twenty years, and has a keen interest in developing students' 
engagement with research methods. Her research interests include sectoral comparisons college based higher education and university settings, and dance psychology. 


\title{
Degrees of Freedom: College Based Higher Education Students' Choices and Views on the Top-up Mode of Higher Education
}

\begin{abstract}
Higher education has for many years been offered to students in the UK at a range of different institution types, one such being colleges of further education. Higher education offered at further education colleges (FECs) differs in many ways from that offered in a university setting. One way in which it differs greatly is the mode of provision. Traditional degrees offered at universities are typically a commitment to a named three-year programme of study. Provision through FECs differs as students typically enrol on a two-year associate degree, either a Higher National Diploma or Foundation degree. Students may then decide to top-up their associate degree to full Bachelor's degree at either their FEC or at partnered universities $(2+1$ mode). This research sought to investigate what factors students believed to be important when making course choices, and their reflection on the course type they chose. It was found that associate degree students tended to remain at the FEC if top-up options were available, and indicated a preference for the flexibility of the $2+1$ mode. Factors that the majority of students deemed as important in their choice of top-up course was their career potential; students remaining at colleges were also concerned about the continuity of their educational experience and course content.
\end{abstract}

College-based higher education; progression; decision making; foundation degree 


\section{Introduction}

Higher Education (HE) within the United Kingdom has traditionally comprised undergraduate degrees at universities consisting of three-year full time qualifications, or fouryear sandwich courses involving a year in placement. The HE landscape changed in the 1990s through the advent of the Foundation Degrees (Fd), similar in construction to the Higher National Diplomas (HND). These associate degrees are typically two-years full time undertaken in Further Education Colleges (FECs) delivered in partnership with a university with degree awarding powers (Foskett 2005). Although a qualification in their own right, once completed students may opt to top-up to a full bachelor's degree through an additional year of study. The final year of study was generally undertaken at the partner university, although many colleges now offer final year top-up routes for their associate degrees to allow students continuity of study; a process that we are referring to as the $2+1$ mode.

The purpose of this paper is to provide an insight into the dynamics of student choice by enquiring into the decision making processes of a cohort of Level 5 students approaching the end of their associate degree.

\section{Evolution of Higher Education}

In traditional higher education students commit to a three-year degree programme. The Dearing Report suggested that while this traditional in-depth study of a narrow field may suit some students, this may not appeal to all, and may not be either useful or suitable (NCIHE 1997). The report encouraged greater breadth of study, whilst noting that this may mean taking longer to complete degree level study. Although traditionally universities were seen as the main providers of $\mathrm{HE}$, there is a strong history of $\mathrm{HE}$ provision within college settings through courses such as Higher National Certificate (HNC) and Higher National Diploma (HND) (Parry and Thompson 2002), courses that met some of the needs outlined by Dearing. 
This approach has been retained throughout on-going changes to the nature of HE in England (Scott 2009) through the development of Foundation Degrees (Fds) being offered through collaborative arrangements between HE Institutions (HEIs) and FECs. This new wave of associate degrees helped provide necessary extra capacity to accommodate expansion (NCIHE 1997, Parry 2003), and increased the range and local availability of HE provision with enhanced progression routes, both within the colleges and into the collaborating HEIs. Foundation degrees were introduced (HEFCE 2000) with the dual purposes of meeting a perceived graduate level skill shortage and enhancing the affordability of HE, whilst simultaneously addressing the government's target of 50\% HE participation rate for $18-30$ year olds by 2010 (Parry 2003, Stevenson and Bell 2009, Stanton 2009). Superimposed on the existing system of HNDs, previously the core of FE colleges' HE work (Parry 2003), the dynamic growth of Fds (Scott 2009) resulted in a decline in HND and HNC enrolments (Harvey 2009). The rapid growth in CBHE provision since the introduction of the foundation degree seems to have plateaued, and has remained stable at about ten percent of HE students since 2010 (HEFCE 2010, HESA 2007, HESA 2011). This trend is not only observed in the English HE system, but has been observed internationally in American Community Colleges and Australian Technical and Further Education institutions. Wheelahan and Davis (2017) suggest that although this form of HE offers more supportive and flexible delivery, to help skill students for the workplace, it does so with the loss of credibility carried by the universities. As college education is also governed by partnered universities the colleges do not have the power to change or influence the market, leading to a stratified approach to education.

\section{The Emergence of Foundation Degrees}

Stanton (2009) considers whether traditional higher education meets the needs of learners within a changing educational environment and evolving employment contexts. He 
distinguishes this from 'higher-level vocational education', such as Fds, which offer a vocational route that is more flexible. Wilson, Blewitt, and Moody (2005) note that Fds were intended to offer flexible modes of study, through part-time and distance routes, thus making them attractive to students who would not have followed the traditional three-year undergraduate route. This flexibility is supported by Ooms, Burke, Marks-Maran, Webb, and Cooper (2011), who found Fds were perceived as allowing students to fit study around work and family commitments, showing success in meeting the needs of widening participation students. It was anticipated that these new degrees would largely be taught in FE colleges working in collaboration with HEIs (DfES 2003), as documented by Foskett (2005); the HEI would provide a progression route for third year honours degree study (Parry 2003).

Designed as a two-year, usually vocationally based HE qualification, employer engagement was integral to the development of Fds and a condition of validation (QAA 2010). Employer involvement is identified in the design and review of programmes and seen as beneficial in programme delivery and for assessment, particularly workplace monitoring of students (DfES 2004, QAA 2015). However establishing and sustaining the required level of employer engagement has been consistently identified as problematic (QAA 2005, Rowley 2005, Edmond, Hillier, and Price 2007). Employer involvement is noted as an area for development (Greenwood and Little 2008, Yorke and Longdon 2010). More recently a review of Fd provision in Wales praised employer engagement in some cases, but still identified this as an area for development for others (QAA 2013). So the growth of Fds (Harvey 2009, Scott 2009) has not been without its challenges.

\section{Foundation Degree Progression}

Foundation degrees were seen as part of a ‘vocational ladder of opportunity' leading on from school-based work experience and vocational qualifications to higher education as well as employment (DfEE 2001, 6). As such they represented a terminal qualification in their own 
right, but also offered a named progression route to a full degree. More recently it has been suggested that Fds represent a transitional qualification (Ooms et al. 2011), as there is evidence that students view Fds as a 'means to an end', a progression route towards other qualifications (Greenbank 2009, 266). A DfES (2004) evaluation of 841 full and part-time students, reported that $31 \%$ had chosen the Fd to gain a higher education qualification, with $21 \%$ specifying progression to an honours degree as their reason. Subsequent studies suggest that Fds may serve as a route towards further study for a majority of students. Harvey (2009) notes that over $50 \%$ of Fd students progressed on to an Honours degree, while Higher Education Funding Council for England (HEFCE 2010) figures show progression is higher for full-time Fd students (59\%) than part-time (42\%). Indeed, in a study of over 5,000 fulltime Fd students, Higgins, Artess, and Johnstone (2010) found that $70 \%$ were intending to undertake further study, while an earlier study of 639 full and part-time students reported $83 \%$ wanted to continue studying beyond their Fd (Jackson and Tunnah 2005). It would seem that students appreciate the opportunities for HE study which Fds offer, and are keen to pursue these.

Unlike university students enrolled on a traditional three-year programme, CBHE student transition to their final year is not always smooth. Physical, social and academic factors have been identified as relevant to successful transition. Apart from having to find their way around a new location, transitioning students may be over-awed by the size of the new institution after the 'comfortable' surroundings of the FEC (Winter and Dismore 2010). Furthermore there is the challenge of integrating socially with an already established student group (Pike and Harrison 2011), though many continue to socialise with others from their FEC (Winter and Dismore 2010).

Students entering HE study have to adjust to studying at a different institution and at a different level (Greenbank 2007), these are issues which confront many students in their first 
year at an HEI (Griffiths, Winstanley and Gabriel 2005, Harrison 2006, Winter and Dismore 2010) but may be duplicated for those transitioning from CBHE to a university. Although this may be a concern for students, evidence suggests they are academically capable and well prepared (Pike and Harrison 2011, Morgan 2015). However the context is more complex as Fds may be more vocational in orientation, attracting non-traditional students for whom the transition to an HEI with a different institutional ethos has been shown to be problematic (Rowley 2005, Morgan 2015). Such stressors may be mitigated by the option to complete the full degree at the FEC.

The difference in institutional ethos is not solely perceived as a problem for students, research has identified structural differences between college and university HE. Although both may be providing comparable higher education courses, there are clear differences between the types of provision. At a structural level higher education tends to be only marginally represented in the types of educational provision offered by colleges, whereas for universities it is the mainstay of their approach. As such CBHE lecturers suggest that their HE provision is required to fit into systems developed for further education courses (Turner, McKenzie, and Stone 2009), leading to CBHE lecturers reporting not being understood by their managers, (Feather 2012), and not supported in their role (Feather 2010). This mismatch of purposes is also reflected in the remit of CBHE teachers where there are limited opportunities to undertake research (Turner, McKenzie, McDermott, and Stone 2009).

\section{Student Perceptions of Associate Degrees}

The 2+1 mode, coupled with the recommendation from the Further Education Development Agency (FEDA) that Fds should be broad, rather than linked to specific vocational routes, can offer students flexibility in choosing their final degree (Harvey 2009). Although every Fd has an articulated progression route, students do not have to follow this; they may choose to follow up areas of interest that they have developed during their study. So not only may 
college provision be more flexible in response to policy changes, it may also offer greater flexibility at the individual level through the $2+1$ mode. While non-traditional students may value the flexibility offered by Fd study, it may also be appealing to school leavers who may welcome the opportunity to keep their options open a little longer. Jackson and Tunnah (2005) report that the Fd was the first choice for $73 \%$ of respondents in their study. While Higgins, Artess, and Johnstone (2010) found that over $65 \%$ of students would choose to study same course if they were starting again, suggesting a high level of satisfaction with what the Fds offered. Interestingly Higgins, Artess, and Johnstone (2010) found that the institution choices of the full time Fd students in their research were based on wanting to study a particular course, rather than the reputation or ranking of the institution concerned. Though there were differences between groups of students in the factors influencing their choice, with younger (under 26) students' choices determined more by interest in the subject, while choices for older student were more likely to be determined by perceived employment prospects.

\begin{abstract}
Aim
The aim of the research was to examine the multiple course choice decisions made by CBHE students. This study focused on Level 5 associate degree students' choices of Level 6 destinations, as well as reflection on their initial choice of study mode.
\end{abstract}

\title{
Methodology
}

\section{Design}

Questionnaires were designed for completion by Level 5 CBHE students studying at an English FE college. The college has a twenty year long history of providing CBHE in 
partnership with a university in the adjacent county, delivering 45 associate degrees (Fds and HNDs), and ten top-up degrees that have been designed to allow for progression from a range of the associate degrees.

\section{Materials}

The questionnaire was designed using a combination of open and scaled questions. The first section dealt with demographic information such as age, gender and current course of study. The second part of the questionnaire allowed for open responses as to what the most important factor was in the students' decision making process, and how they felt about their choice of associate degree route followed by an application to a top-up year ( $2+1$ mode). In addition to this the students were asked what progression choices were open to them, and what decision they had ultimately made.

\section{Participants}

Contact was made with students via an email from their tutor with the questionnaire web link attached. The sample consisted of 43 Level 5 students (11 males and 32 females) with an average age of 28.5 (range 19-59). Responses were drawn from 10 associate degrees (Fds and HNDs) including natural and social sciences, early years education, law, sport and computing.

\section{Procedure}

The survey was delivered through an electronic platform as it has shown to be an effective way of accessing a range of participants quickly and economically with instant feedback (Cantrell and Lupinacci 2007). As the preferred method of communication outside of contact hours is through the college email system, and students are regularly contact via their tutors with course related information, the tutors were deemed a suitable conduit for the survey link.

\section{Data Analysis}


The responses to the open questions were analysed through the application of thematic analysis, with codes derived at a concept level. References to the factors for choosing the Level 6 course were tallied and converted to percentages in order to make meaningful comparisons between students moving to university and those remaining at the FEC. Chisquare tests were applied to the destination data.

\section{Discussion of Findings}

\section{Top-up Options and Ultimate Destinations}

Sixteen per cent of the students indicated that they would not be progressing on to a Level 6 course immediately, either due to offers of employment or taking a gap year. Interestingly two-thirds of those going straight into employment were enrolled on associate degrees that had no local top-up route. As the nearest university offering a suitable top-up is sixty miles away it may be that these students are unable to move or commute, and feel that their only option is to leave education in favour of employment, although they may not be able to apply for graduate positions.

Of the 37 (84\%) Level 5 students who did indicate that they would be progressing on to a top-up year $62 \%$ were remaining at the college and $38 \%$ were transferring on to a university. The proportion of students intending to progress in this study is greater than the fifty per cent progression reported by HEFCE (2010). This suggests that a greater number of students see associate degrees as a stepping stone to the full bachelor's degree than has been previously reported (Harvey 2009), and is more in line with the intentions of students as reported in studies by Jackson and Tunnah (2005) and Higgins, Artess, and Johnstone (2010). 
The associate degrees that the Level 5 students were studying were grouped into three categories based on the range of Level 6 options open to them. These categories were:

- Single - where only one university progression course is open to them, and no internal college top-up course is available.

- Binary - where one internal college and one university top-up course is available.

- Multiple - where there are many internal college and university top-up options available.

When these options were associated with the actual destination chosen by the students there were significant differences $\left(x^{2}=14.2, \mathrm{df}=2, p=.001\right)$. When no internal college option was available all students progressed to the university although this group were more likely not to progress immediately by either taking a gap year or taking paid employment. Whereas when they had a binary choice between one internal and one external route $71 \%$ chose to remain at the college, and similarly when multiple internal and external routes were available $78 \%$ chose to remain (Figure 1).

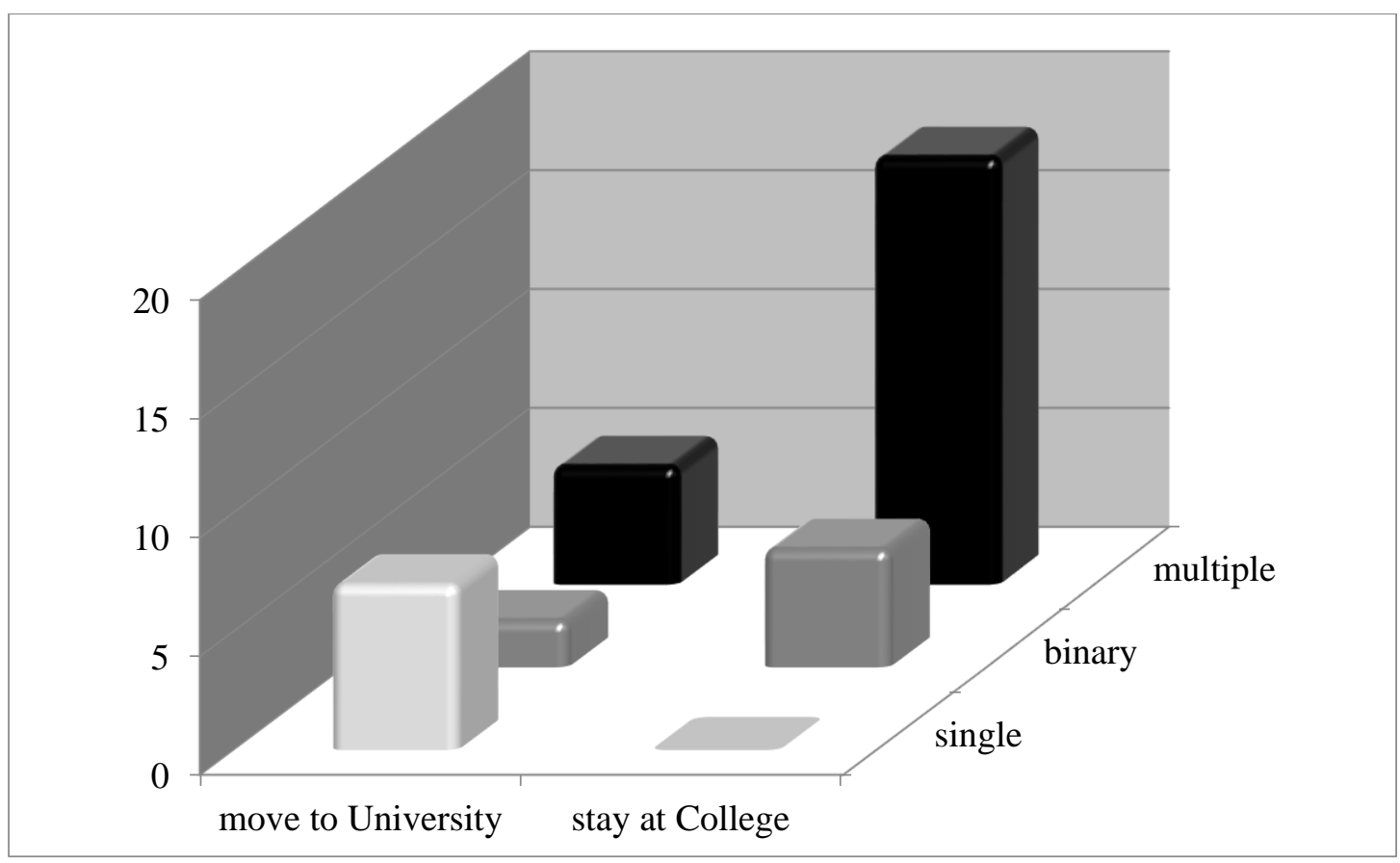

Figure 1. Student decisions based on options available 
This suggests that students prefer the continuity of educational experience that the college offers, rather than the moving on to pastures new. Continuity of place, being close to home, but also the familiarity of staff and facilities were cited as factors that were important in their decision making process. A finding that has been similarly reported in research that considers the reflections of students who have progressed on to university from associate degrees in FECs ( Simm, Marvell, Schaaf, and Winlow 2012, Winter and Dismore 2010), but has so far not been examined at the decision making stage.

When asked what was the most important factor in their decision of top-up route, those who were moving to a university referred to factors that would be experienced after graduation, such as the status of the qualification and their potential career prospects. The most common responses were 'to have a full degree' or 'for future career prospects'. Although the students remaining at the college also saw these as highly important factors, their responses were grounded in the educational experience, such as discipline and course content.

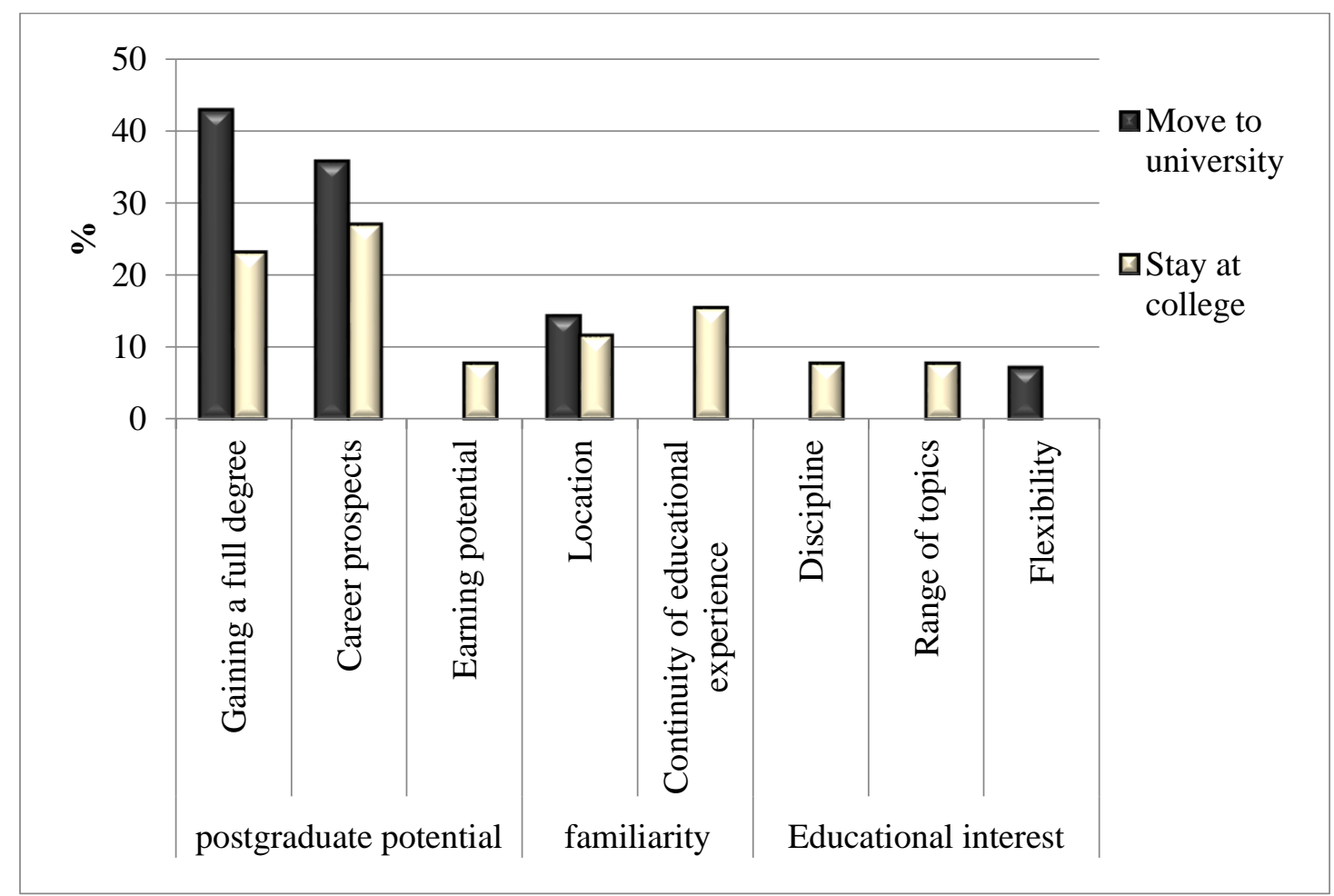


Figure 2. Proportion of students responses when asked what the important factors were in their choice based on ultimate destination

As the majority of respondents cited the importance of the resultant qualification and their career prospects as a vital factors in their choice, this suggests that students perceive the degrees to be of equal value regardless of the institution at which they are delivered. This challenges the assumptions of Creasy $(2012,49)$ who suggests that due to a focus on teaching and learning rather than research, colleges may be 'undermining the integrity of HE'.

\section{Student Reflections on their Choice of Degree Mode}

Students were asked an open question regarding how they felt about the decision they made regarding their choice of a two-year associate degree plus a top-up option $(2+1$ mode). As can be seen in Table 1 there was very strong support for the $2+1$ mode, respondents most frequently reporting that they were 'happy' that they had chosen the route, or that it was a 'good' choice. Their satisfaction seems to be based on the flexibility that the $2+1$ mode provides, which may mitigate against course related factors implicated in withdrawals from three-year degree programmes (Harrison 2006). As can be seen from this typical response, respondents believed the $2+1$ mode allowed them to deviate from their initial path:

It gives you a chance to change directions and rethink your career path. Also new courses have been added ... so you can think about other ideas and also you could choose to do the third year in a different university which may further career choices.

(Female, FdA Children and Young Persons Workforce)

An alternative reason for preferring the $2+1$ mode was 'because it gives me the option of specialising in my top-up year, instead of doing the exact same course for 3 years' (Male, Fd Digital Visualisation), or even the possibility of taking a study break between Level 5 and 6. 
Substantially fewer students were in favour of having opted for a full three-year degree, although those who indicated a preference for the traditional model did not go into detail as to why this would have been preferable. One explanation may be that $20 \%$ of respondents reported periods of concern during the second year when having to go through the decision making process, due to lack of options available.

Table 1. Students' reflections on their choice of the $2+1$ mode of study

\begin{tabular}{llr}
\hline \multirow{2}{*}{ Preference for the } & Positive expression about their decision & 17 \\
\cline { 2 - 3 } Preferences for & Appreciation of the flexibility of study choices & 23 \\
\hline \multirow{2}{*}{ full 3 year degree } & Would have preferred a single degree & 5 \\
\cline { 2 - 3 } & Does not like decision making & 1 \\
\hline \multirow{3}{*}{ Concerns } & Fd/HND too restrictive without a top-up & 4 \\
\cline { 2 - 3 } & Worry by lack of top-up options & 2 \\
\cline { 2 - 3 } & Unaware of 3 ${ }^{\text {rd }}$ year option & 1 \\
\cline { 2 - 3 } & Relief at finding a top-up & \\
& &
\end{tabular}

What colleges offer through associate degrees are a novel approach to degree construction. The fact that students embark on a two-year course which they then have the choice to convert into a full degree, not necessarily in the same discipline as their initial associate degree, is unlike the route undertaken by those enrolling on a three-year honours degree. Overwhelmingly students showed a preference for this mode of study, most especially with the flexibility it affords. On consideration of the type of students who typically enrol on associate degrees, often more female and mature students, this flexible approach may be a more logical choice as these learners may lack confidence in returning to education, therefore are only committing to two years of study at the outset. It also allows students to taste 
different aspects of their chosen field of study, then specialise in their final year, rather than committing to a full three years without feeling fully confident as to whether it is the right course of study for them.

What was also revealed were issues of worry with respect to what opportunities were available to top-up, especially where there were no local progression routes. This was compounded by the importance that they placed on the locality and familiarity of the institution. Proximity of the institution (Simm et al. 2012, Burton, Lloyd, and Griffiths 2011) and familiarity of people and processes (Greenwood and Little 2008, Greenbank 2009, Winter and Dismore 2010) have been shown to be issues of importance to students undertaking HE study in FE colleges. For those who did not have access to local top-up routes it seems that they experienced more anxiety at having to make the decision about whether to complete their education, and then to make commitments to move or commute. Any student choosing to continue elsewhere may then have issues with acclimatisation to a new physical, academic and social environment, at a point in their studies when they are undertaking more autonomous learning (Morgan 2015, Simm et al. 2012). Potentially this may impact on their ultimate degree classification by comparison to their performance in more familiar surroundings.

\section{Conclusion}

The purpose of this study was to explore students' reasons for their choices of Level 6 destination and reflections on their initial choice of study mode. This study explores CBHE student perceptions, rather than making direct comparisons of the two modes of study, which may have contributed to the positive responses in favour of the $2+1$ mode. However the 
findings do highlight the importance of flexibility in a course of study, a factor that is not necessarily afforded to those on the traditional three-year degree.

Student preference for continuity of experience, through the availability of Level 6 provision in the FEC, addresses many of the transition concerns identified in earlier research. Having experienced college HE provision students were confident that their ultimate qualification would allow them to pursue their graduate aims, regardless of the institution type.

University partnerships may wish to consider more flexible approaches to course construction and progression to allow students the opportunity to maximise their potential within the colleges.

\section{References}

Burton, K., M. Lloyd, and C. Griffiths. 2011. "Barriers to learning for mature students studying HE in an FE college." Journal of Further and Higher Education 35 (1):2536. doi: 10.1080/0309877X.2010.540231.

Cantrell, M. A., and P. Lupinacci. 2007. "Methodological issues in online data collection." Journal of Advanced Nursing 60 (5):544-549. doi: 10.1111/j.13652648.2007.04448.x.

Creasy, R. 2012. "HE lite: exploring the problematic position of HE in FECs." Journal of Further and Higher Education 37 (1):38-53. doi: 10.1080/0309877X.2011.644772.

DfEE. 2001. Opportunity and Skills in the Knowledge-Driven Economy: a final statement on the work of the National Skills Task Force from the Secretary of State for Education and Employment. London: Department for Education and Employment

DfES. 2003. The future of higher education. London: HMSO.

DfES. 2004. Evaluation of Foundation Degrees: Final Report. York Consulting Limited. 
Edmond, N., Y. Hillier and M. Price. 2007. "Between a rock and a hard place. The role of HE and foundation degrees in workforce development." Education + Training 49 (3):170-181. doi: 10.1108/00400910710749305

Feather, D. 2010. "A whisper of academic identity: an HE in FE perspective. Research in Post-Compulsory Education" 15(2):189-204. doi: 10.1080/13596741003790740

Feather, D. 2012. "Do lecturers delivering higher education in further education desire to conduct research?" Research in Post-Compulsory Education, 17(3):335-347. doi. $10.1080 / 13596748.2012 .700110$

Foskett, R. 2005. "Collaborative Partnership in the higher education curriculum: a crosssector study of foundation degree development." Research in Post-Compulsory Education 10 (3):351-372. doi: 10.1080/13596740500200210.

Greenbank, P. 2007. "From foundation to honours degree: the student experience." Education + Training 49 (2):91-102. doi:10.1108/00400910710739450.

Greenbank, P. 2009. "Foundation degree students and their educational decision-making." Education + Training 51 (4):259-271. doi: 10.1108/00400910910964557.

Greenwood, M., and B. Little. 2008. Report to Foundation Degree Forward on the Impact of Foundation Degrees on Students and the Workplace. London: Centre for Higher Education Research and Information.

Griffiths, S.D., D. Winstanley and Y. Gabriel 2005. "Learning shock: The trauma of returning to formal learning." Management Learning 36 (3):275-97. doi: 10.1177/1350507605055347.

Harrison, N. 2006. "The impact of negtaive epxeriences, dissatisfaction and attachement on first year undergraduate withdrawal." Journal of Further and Higher Education 30(4):377-391. doi:10.1080/03098770600965383. 
Harvey, L. 2009. Review of research literature focused on foundation degrees. Litchfield: Foundation Degrees Forward.

HEFCE. 2000. Foundation Degree Prospectus. Bristol: Higher Education Funding Council for England.

HEFCE. 2010. Foundation degrees: Key statistics 2001-02 to 2009-10. Bristol: Higher Education Funding Council for England.

HESA. (2007). All student enrolments on higher education courses by level of study, mode of study and domicile, 2001/02 to 2005/06 (Table 1) Retrieved Statistical First Release 153, from http://www.hesa.ac.uk

HESA. (2011). All student enrolments on HE courses by level of study, mode of study and domicile 2005/06 to 2009/10 (Table 1) from http://www.hesa.ac.uk

Higgins, H., J. Artess, and I. Johnstone. 2010. Students' experiences of full-time Foundation degrees. Lichfield: Higher Education Careers Services Unit.

Jackson, C., and E. Tunnah. 2005. The information, advice and guidance needs of foundation degree students - report of an AGCAS survey. Sheffield: Association of Graduate Careers Advisory Services.

Morgan, J. 2015. "Foundation degree to honours degree: the transition experiences of students on an early years programme." Journal of Further and Higher Education 39 (1):108-126. doi: 10.1080/0309877X.2013.817005.

NCIHE. 1997. Higher Education in the Learning Society: Summary Report. London: HMSO.

Ooms, A., L. M. Burke, D. J. Marks-Maran, M. Webb, and D. Cooper. 2011. "Students' perceptions of foundation degrees." Journal of Further and Higher Education 36 (3):403-421. doi: 10.1080/0309877X.2011.632821.

Parry, G. 2003. "Mass Higher Education and the English: Wherein the Colleges?" Higher Education Quarterly 57 (1):308-337. doi: 10.1111/j.0951-5224.2003.00250.x. 
Parry, G., and A. Thompson. 2002. Closer by degrees: the past, present and future of higher education in further education colleges. London: Learning and Skills Development Agency.

Pike, A. and J. Harrison. 2011. "Crossing the FE/HE divide: the transition experience of direct entrants at Level 6." Journal of Further and Higher Education 35 (1):55-67. doi:10.1080/0309877X.2010.540315.

QAA. 2005. Employer Engagement. Emerging Practice from QAA reviews from http://www.qaa.ac.uk

QAA. 2010. Foundation Degree qualifaction benchmark from http://www.qaa.ac.uk

QAA. 2013. Report on the Review of Foundation Degrees in Wales, 2012-13 from http://www.qaa.ac.uk

QAA. 2015. Characteristics statement: Foundation Degree from http://www.qaa.ac.uk Rowley, J. 2005. "Foundation degrees: A risky business?" Quality Assurance in Education $13(1) ; 6-16$.

Scott, P. 2009. "On the Margins or Moving into the Mainstream? Higher Education in Further Education in England." Higher Education Quarterly 63 (4):402-418. doi: 10.1111/j.1468-2273.2009.00442.x.

Simm, D., A. Marvell, R. Schaaf, and H. Winlow. 2012. "Foundation Degrees in Geography and Tourism: A Critical Reflection on Student Experiences and the Implications for Undergraduate Degree Courses." Journal of Geography in Higher Education 36 (4):563-583. doi: 10.1080/03098265.2012.692075.

Stanton, G. 2009. "A View from Within the English Further Education Sector on the Provision of Higher Education: Issues of Verticality and Agency." Higher Education Quarterly 63 (4):419-433. doi: 10.1111/j.1468-2273.2009.00441.x. 
Stevenson, H., and L. Bell. 2009. "Introduction - Universities in Transition: Themes in Higher Education Policy." In The Future of Higher Education: Policy, Pedagogy and the Student Experience, edited by L. Bell, H. Stevenson and M. Neary. London: Continuum.

Turner, R., L. McKenzie, and M. Stone. 2009. "'Square peg - round hole’: the emerging professional identities of HE in FE lecturers working in a partner college network in south-west England." Research in Post-Compulsory Education 14(4):355-368. doi: 10.1080/13596740903360919.

Turner, R., L. McKenzie, A. McDermott, and M. Stone. 2009. "Emerging HE cultures: perspectives from CETL award holders in a partner college network." Journal of Further and Higher Education 33(3):255-263. doi:10.1080/03098770903026172.

Wheelahan, L.\& Davis, W.G. (2017). "Higher education lessons from across oceans" Paper presented at the Association of Colleges (AoC) Third Research and Scholarship in College Higher Education Conference, $27^{\text {th }}$ June 2017, Birmingham.

Wilson, J., J. Blewitt, and D. Moody. 2005. "Reconfiguring higher education: the case of foundation degrees." Education + Training 47 (2):112-123. doi: 10.1108/00400910510586533.

Winter, J., and H. Dismore. 2010. "Investigating the experiences of foundation degree students progressing to an honours degree: an integrated approach." Journal of Further and Higher Education 34 (2):253-270. doi: 10.1080/03098771003695502.

Yorke, M. and B. Longdon. 2010. Learning, juggling and achieving: Students' experiences of part-time Foundation degrees. Lichfield: Foundation Degree Forward. 